\title{
Prácticas docentes en la comprensión de múltiples textos en educación secundaria
}

\section{Teaching practice in the comprehension of multiple texts in junior high school}

DOI: https://doi.org/10.32870/dse.v0i24.957

Xóchitl Gómez Cordero*

Norma Alicia Vega López**

\begin{abstract}
Resumen
La comprensión de múltiples textos (CMT) o comprensión intertextual, es una de las principales habilidades de pensamiento de orden superior, como la selección, evaluación, integración y síntesis de información proveniente de múltiples textos y formatos. El objetivo del presente artículo fue describir las prácticas docentes (noción CMT, prácticas de enseñanza y evaluación) de la comprensión intertextual por modalidad educativa de los profesores de español en educación secundaria. El método utilizado fue cualitativo, de corte transversal exploratorio y un diseño de casos cruzados por modalidad de secundaria. La técnica de investigación utilizada fue la entrevista semiestructurada, aplicada a 19 profesores. A través de la técnica de análisis de contenido, los resultados muestran que los profesores de secundarias técnicas y privadas, aun cuando tienen una noción de la CMT, describen procesos de enseñanza concernientes a la comprensión de un solo texto. Referente a la enseñanza de la evaluación de las fuentes, la mayoría coincide en no realizar tal proceso debido al desconocimiento del tema y falta de tiempo o recursos necesarios en la institución. Estos hallazgos sugieren reflexionar acerca de las necesidades de formación del profesorado.
\end{abstract}

Palabras clave: comprensión lectora - enseñanza de la lengua - educación secundaria - profesores en servicio - prácticas educativas.

\section{Abstract}

Multiple-text comprehension (CMT) or intertextual comprehension is one of the main thinking skills of a higher order, such as the selection, evaluation, integration, and synthesis of information from multiple texts and formats. The aim of this article was to analyze the teaching practices (CMT notion, teaching and evaluation practices) of intertextual comprehension by educational modality of Spanish teachers in junior high school. The method was qualitative, exploratory, cross-sectional, and with a cross-case design by

\footnotetext{
* Doctora en Políticas Educativas. Líneas de investigación: Evaluación de políticas educativas; prácticas de enseñanza. Profesora de Tiempo Completo en la Universidad Autónoma de Tamaulipas. México.xgomez@docentes.uat.edu.mx

** Doctora en Psicología de la Educación. SNI. Líneas de investigación: Lectura y escritura a través del currículo. Profesora de Tiempo Completo en la Universidad Autónoma de Tamaulipas. México. navegalo@docentes.uat.edu.mx
} 
junior high school modality. The research technique used was a semi-structured interview applied to 19 teachers. Through the technique of contents analysis, our results show that even when they have just a notion of CMT, teachers of technical and private junior high school describe teaching processes concerning the understanding of a single text. Regarding the teaching of the evaluation of the sources, most admit that they do not do this due to lack of knowledge of the subject and lack of the time or resources needed in the institution. These findings suggest the need to reflect on the training needs of teachers.

Keywords: reading comprehension - language teaching - junior high school - inservice teacher education - educational practices.

\section{Introducción}

Comprender y aprender de múltiples textos (comprensión intertextual) es una competencia clave para funcionar como individuos alfabetizados en el siglo XXI, implica ser capaces de inferir y analizar las relaciones intertextuales (posiciones y contradicciones) a través de las diferentes fuentes de información, así como evaluar de forma crítica la fiabilidad y relevancia de la información para la resolución de problemas presentes en el ámbito escolar, profesional y de la vida diaria (Britt et al., 2018; Goldman, Snow, 2015). Esto supone un reto para la formación de lectores competentes, por consiguiente, el docente es un agente toral para la implementación de políticas y programas de estudios orientados al desarrollo de tales competencias a través de su práctica docente.

En México, en educación secundaria, a partir de la Reforma Integral de Educación Secundaria en 2002, se estableció como parte de la política educativa del sexenio 2001-2006 un perfil del alumno que incluía competencias transversales de aprendizaje permanente y de orden superior, es decir, el desarrollo del pensamiento crítico y competencias comunicativas como la oralidad, la comprensión lectora intertextual y la escritura (Secretaría de Educación Básica, Normal, 2002). Dichas competencias siguen vigentes en el Plan de estudios 2017 y se abordan principalmente a través de la enseñanza de la lengua, el español (SEP, 2017: 235).

Los estudios de las prácticas docentes de la comprensión lectora en educación básica (primaria y secundaria), se enfocan en dos grandes líneas de indagación: en primer lugar, las prácticas enfocadas a aprender a comprender, que se centran en el aprendizaje de la lectura -adquisición- y la formación de lectores competentes, principalmente en la asignatura de la enseñanza de la lengua. En segundo lugar, las prácticas orientadas a leer para aprender/comprender los contenidos disciplinares (Bustos et al., 2017). Dichas líneas se han abordado desde diferentes perspectivas teórico-metodológicas, a saber, aproximaciones cognitivas con énfasis en la enseñanza explícita de estrategias para la comprensión (Ness, 2011); socioculturales, cuyo 
foco son las prácticas de lectura, las ayudas pedagógicas, el discurso áulico (Cosío, Hernández, 2016); sociocognitivas, enfocadas en el análisis de la interacción profesor-alumno en torno a la tarea de lectura a partir de tres dimensiones independientes: qué (contenidos instruccionales de tipo conceptual/representaciones mentales, y procedimentales/estrategias), quién es el responsable (grado de autonomía del alumno en la elaboración del contenido) y cómo (formas de organización de la interacción profesor-alumno-tarea, estrategia didáctica) (Rudell, Unrau, 2013; Sánchez et al., 2008).

Por ejemplo, en el contexto español el estudio de Broncano et al. (2011), desde una aproximación sociocognitiva y cualitativa, indagó las prácticas de cuatro profesores de secundaria para favorecer la comprensión lectora intratextual, en una clase de historia. Mediante una metodología cualitativa y como foco de análisis las unidades didácticas (sesiones y actividades), identificaron tres situaciones: 1) Realización colectiva de tareas o lectura integrada, es decir, leer un texto para realizar una tarea o ejercicio en el aula, donde los alumnos no reciben supervisión y/o ayudas para el proceso de interpretación del texto. 2) Revisión colectiva de tareas, se evalúa el resultado logrado, pero no el proceso. 3) Lectura colectiva: a) con comentario, el profesor interpreta el texto; $b$ ) genuina, el profesor solicita a los alumnos la lectura en voz alta, y supervisa la interpretación de ésta a través de cuestionamientos; c) genuina-mental, la lectura se realiza en silencio y la construcción de significados es dirigida por el profesor mediante preguntas o tareas que los alumnos deben responder públicamente. Esta última práctica de lectura, considerada como elaborativa, fue la menos frecuente en las sesiones observadas.

En Chile, Iturra (2015) realizó un estudio cualitativo con profesores de primaria clasificados como competentes y básicos, según el sistema de evaluación docente. A partir de 30 grabaciones, indagó las prácticas de enseñanza de la lectura en la asignatura de lengua. Siguiendo una estrategia de análisis del discurso áulico, clasificó las prácticas en tres momentos: antes, durante y después de la lectura. Los resultados mostraron que: en la fase antes de la lectura, los profesores competentes realizaron actividades de planificación y explicitación de la tarea de lectura y activación de conocimientos previos. En la fase durante la lectura, ambos grupos de profesores realizaron actividades de ejecución de la lectura, interpretación de partes del texto y revisión del significado de palabras; no obstante, casi la mitad de los profesores no generaron espacios para la supervisión de la comprensión, es decir, la elaboración de procesos inferenciales. En la fase después de la lectura, los profesores competentes asignaron tareas o preguntas acerca de la comprensión del texto y las evaluaron a través del diálogo o exposiciones de los alumnos; sin embargo, el autor señala que en esta fase los profesores mostraron escasa frecuencia del uso de estrategias, como la discusión, mapas conceptuales, etc., necesarias para promover procesos cognitivos de mayor complejidad.

En México, la investigación se ha enfocado primordialmente en la educación primaria, por ejemplo, Treviño et al. (2007), mediante el uso de un cuestionario, señaló las prácticas de los 
profesores como procedimentales/literales (identificación de ideas principales, elaboración de resúmenes), que distan de las habilidades necesarias para llevar a cabo procesos de comprensión que conlleven un aprendizaje disciplinar. El estudio de Cossío y Hernández (2016) indagó, mediante cuestionarios y entrevistas, cómo median las teorías implícitas (TI) de enseñanza-aprendizaje las prácticas docentes de los profesores de primaria. Los resultados señalaron, en primer lugar, que aun cuando los profesores manifiestan principalmente una TI constructivista, su discurso no revela un dominio conceptual de las propuestas educativas puesto que éstas se instituyen rígidamente, limitando una reflexión profunda sobre las mismas. Lo anterior "provoca que los profesores no cuenten con los suficientes elementos para resignificar sus representaciones del aprendizaje y, por lo tanto, sus prácticas de enseñanza se muestran alejadas de una postura predominantemente constructiva" (Cossío, Hernández, 2016: 1,160). En segundo lugar, profesores con $\mathrm{Tl}$ constructivista se encuentran en proceso de consolidación, revelando prácticas de enseñanza orientadas a un aprendizaje centrado en el estudiante, mientras que los profesores con TI directa e interpretativa se caracterizan por prácticas de enseñanza centradas en la transmisión de contenidos.

No obstante, los estudios de las prácticas docentes de la comprensión de múltiples textos en nivel secundaria, en México y otros países, han recibido menos atención, excepto en el contexto anglosajón, donde la investigación realizada por Litman et al. (2017), con profesores de asignaturas de lenguaje (inglés), historia y ciencias, revela que las prácticas docentes se caracterizan por destinar mayor tiempo a fomentar la adquisición de conocimientos factuales de las disciplinas y menor tiempo a generar actividades y/o tareas que favorezcan el desarrollo de habilidades para la argumentación, a través de la comprensión de múltiples textos. En resumen, la literatura muestra la complejidad y variedad de dimensiones de análisis para caracterizar las prácticas docentes, así como también la problemática existente con respecto a favorecer en mayor medida espacios para el aprendizaje/comprensión significativa de los contenidos y las habilidades necesarias para ello. Por lo tanto, es necesario avanzar en la investigación de las prácticas docentes de la CMT, que permitan entender la problemática, a fin de determinar y orientar las necesidades de formación del profesorado. El objetivo del presente estudio fue describir las prácticas docentes de la comprensión de múltiples textos por modalidad educativa de los profesores de español en educación secundaria. ${ }^{1}$

\section{La comprensión de múltiples textos}

En el presente estudio, situado en la línea de las prácticas de enseñanza aprender a comprender y acorde con García-Cabrero et al. (2008), concebimos la práctica docente como un conjunto de situaciones/relaciones en el interior del aula, que conforman las acciones de docentes y alum-

1 El estudio se deriva del proyecto: "Prácticas de enseñanza y evaluación de la comprensión lectora de múltiples fuentes en educación secundaria: un estudio mixto", que fue financiado por el Fondo Conacyt-FONSEC INEE \# 289392 y realizado durante 2018 y 2019. 
nos en torno a los objetivos de aprendizaje. Teóricamente, para analizar dichas relaciones y acciones en torno a la enseñanza de la CMT, adoptamos una visión sociocognitiva del fenómeno. En específico, el modelo interactivo sociocognitivo de Ruddell y Unrau (2013: 1017) señala que "la lectura es conceptualizada como un proceso de construcción de significados en el contexto educativo del aula". Este proceso es orquestado por la relación entre el alumno, el profesor, el texto y el contexto áulico-escolar. Con respecto al alumno, se concibe que tiene una experiencia previa acerca de las condiciones afectivas y cognitivas. Las primeras incluyen una variedad de factores como la motivación para leer, valores y creencias socioculturales personales sobre la lectura y la escolarización. Las segundas condiciones explican aspectos como el conocimiento previo del lenguaje, el reconocimiento de palabras y las habilidades de identificación, las estrategias de procesamiento del texto y la comprensión de la interacción social en el aula.

Referente a la enseñanza que realiza el profesor -aspecto que nos ocupa-, éste posee un conocimiento sobre dos dimensiones: 1 ) las afectivas, que incluyen creencias y filosofía de enseñanza e involucran aspectos como la motivación para involucrar a los estudiantes, y la orientación en la enseñanza, que refleja los valores y creencias socioculturales personales; 2) cognitivas, contemplan conocimientos acerca de: $a$ ) la naturaleza de los procesos cognitivos implicados en la comprensión lectora, $b$ ) las estrategias cognitivas y metacognitivas que deben ser enseñadas para el logro de la comprensión, c) métodos de enseñanza conducentes a la naturaleza del contexto áulico. Sobre este último aspecto, Almasi y King (2012) clasifican los métodos como: endógeno (centrado en el alumno), exógeno (centrado en el profesor) y dialéctico (proceso de cesión gradual de la responsabilidad del profesor al alumno). Por su parte, el texto impone una serie de restricciones de carácter lingüístico/discursivo y demanda, para su comprensión, el uso de estrategias diferenciadas acordes a su función comunicativa. Finalmente, en el contexto del aula se delimita el tipo de relaciones y acciones entre los agentes mencionados para la construcción de significados.

En resumen, se requiere que el profesor esté en sintonía con la experiencia previa del alumno, que mediante la planeación incorpore las estrategias para los diferentes géneros textuales, los métodos de enseñanza acordes a la naturaleza del aula, y el diseño de actividades y tareas que permitan la construcción de significados situados socioculturalmente (Ruddell, Unrau, 2013).

En esta línea, a nuestro juicio, el conjunto de conocimientos (cognitivos) que debería poseer el profesor respecto a la construcción de significados intertextuales, se explican a partir de la Teoría del Modelo de Documentos, propuesta por Perfetti et al. (1999), y plantea que el lector construye un conjunto de representaciones mentales acerca de la fuente y su contenido. Referente a la fuente, se considera: la identidad del autor (nombre, estatus, motivaciones para escribir y grupos de trabajo o pertenencia), el contexto (periodo histórico-cultural de creación y credibilidad del medio de publicación), características del texto (estilo del lenguaje y género 
textual), objetivos retóricos (intenciones del autor, p. ej., argumentar, explicar, etc., y la audiencia a la que se dirige).

Cuando los lectores integran la representación de la fuente con su contenido, forman una representación o nodo del documento y, a la vez, establecen vínculos intertextuales de dos tipos: vínculos fuente-fuente a partir de la citación, de la pericia de los autores, de su ubicación temporal y contexto histórico; y vínculos contenido-contenido, que radican en el reconocimiento de las relaciones retóricas en términos de solapamiento, complementariedad o contradicción de la información. Con lo anterior, se forma una representación mental global coherente, denominada Modelo de Documentos (Britt et al., 2013).

\section{Metodología}

El método que se utilizó fue cualitativo, de corte transversal y alcance exploratorio. Se adoptó un diseño de casos cruzados por modalidad de secundaria. ${ }^{2}$ Su elección estriba en que la investigación cualitativa permite el análisis de una práctica -en este caso educativa- a partir del entendimiento de sus participantes, con el fin de mejorarla; también es pertinente cuando existe escasa investigación previa. Por su parte, el estudio de casos se caracteriza por que el "análisis de los datos se centra en un fenómeno" y permite observar sus semejanzas y diferencias (McMillan, 2005: 402).

La técnica de investigación utilizada fue la entrevista y el instrumento de investigación fue un guion de entrevista que se organizó en tres dimensiones: a) Percepción o noción de la lectura comparativa de múltiples fuentes LCMF; ${ }^{3}$ b) Enseñanza de la LCMF; y c) Evaluación de la LCMF. Fue elaborado por las autoras, y su validación consistió en un jueceo por expertos (3 expertos en el tema elaboraron, revisaron y determinaron la preguntas), y un pilotaje de la entrevista con 12 profesores permitió realizar ajustes en los términos utilizados, por ejemplo, los profesores utilizan el término lectura comparativa de múltiples fuentes (LCMF) para referirse a la comprensión de múltiples textos (intertextual). Además, se contextualizaron algunas preguntas aludiendo a las competencias y/o aprendizajes esperados que forman parte de las planeaciones del programa de estudios de español.

\section{Participantes}

El estudio se realizó en Ciudad Victoria, Tamaulipas, estado fronterizo del noreste de México. Participaron 19 profesores de la asignatura de español, de los cuales, tres corresponden a escuelas secundarias generales, nueve a secundarias técnicas, tres a privadas y cuatro a telesecun-

2 La educación secundaria pública en México se clasifica en: Generales (públicas o privadas e imparten materias académicas), técnicas (además de las materias académicas, ofrecen capacitación para actividades agrícolas o industriales) y telesecundarias (presentes en el medio rural).

3 A partir de esta sección utilizamos el término Lectura Comparativa de Múltiples Fuentes LCMF, debido a que es mayormente utilizado por el colectivo de profesores para referirse al constructo teórico de comprensión de múltiples textos. 
daria. Las escuelas fueron seleccionadas a partir de una estrategia de muestreo intencionado de variación máxima (McMillan, Schumacher, 2005), considerando los siguientes criterios de inclusión: a) profesores que laboran en las diferentes modalidades; $b$ ) que tuvieran un mínimo de 3 años de experiencia; $c$ ) el grado de marginación de las escuelas; y d) los resultados de los alumnos por niveles de logro educativo en lenguaje y comunicación de la prueba Plan Nacional para la Evaluación de los Aprendizajes (PLANEA). Es decir, interesó seleccionar profesores que pertenecieran a instituciones que se ubiquen por encima y por debajo del porcentaje promedio de alumnos en los niveles 3 y 4 en el ámbito estatal en la última evaluación de PLANEA (2017), previa a la realización del estudio. En la Tabla 1 se observan las características de los casos analizados.

Tabla 1. Distribución de los informantes por tipo de secundaria

\begin{tabular}{|c|c|c|c|c|c|c|c|c|c|}
\hline \multirow[t]{2}{*}{$\begin{array}{l}\text { Tipo de } \\
\text { secunda- } \\
\text { ria }\end{array}$} & \multirow[t]{2}{*}{$\begin{array}{l}\text { Tipo de } \\
\text { secunda- } \\
\text { ria }\end{array}$} & \multirow[t]{2}{*}{$\begin{array}{l}\text { Tipo de } \\
\text { margina- } \\
\text { ción }\end{array}$} & \multicolumn{3}{|c|}{$\begin{array}{l}\text { Porcentaje de alumnos en } \\
\text { PLANEA (Lenguaje y co- } \\
\text { municación) por niveles }\end{array}$} & \multirow[t]{2}{*}{$\begin{array}{l}\text { Profeso- } \\
\text { res entre- } \\
\text { vistados }\end{array}$} & \multicolumn{2}{|c|}{ Género } & \multirow[t]{2}{*}{$\begin{array}{l}\text { Grado de es- } \\
\text { tudio de los } \\
\text { profesores }\end{array}$} \\
\hline & & & 1 a 2 & 3 a 4 & Total & & $F$ & $M$ & \\
\hline General 1 & General & Media & $85.70 \%$ & $14.30 \%$ & $100 \%$ & 2 & 2 & 0 & Licenciatura (2) \\
\hline General 2 & General & $\begin{array}{c}\text { Baja y muy } \\
\text { baja }\end{array}$ & $72.50 \%$ & $27.50 \%$ & $100 \%$ & 1 & 1 & 0 & Licenciatura (1) \\
\hline Técnica 1 & Técnica & $\begin{array}{c}\text { Baja y muy } \\
\text { baja }\end{array}$ & $39.20 \%$ & $60.80 \%$ & $100 \%$ & 7 & 6 & 1 & $\begin{array}{c}\text { Licenciatura (4) } \\
\text { Maestría (3) }\end{array}$ \\
\hline Técnica 2 & Técnica & $\begin{array}{c}\text { Baja y muy } \\
\text { baja }\end{array}$ & $81.10 \%$ & $18.90 \%$ & $100 \%$ & 2 & 2 & 0 & $\begin{array}{c}\text { Licenciatura (1) } \\
\text { Doctorado (1) }\end{array}$ \\
\hline Privada & Privada & $\begin{array}{c}\text { Baja y muy } \\
\text { baja }\end{array}$ & $22.50 \%$ & $77.50 \%$ & $100 \%$ & 3 & 3 & 0 & $\begin{array}{c}\text { Licenciatura (2) } \\
\text { Maestría (1) }\end{array}$ \\
\hline $\begin{array}{c}\text { Telese- } \\
\text { cundaria } 1\end{array}$ & $\begin{array}{l}\text { Telese- } \\
\text { cundaria }\end{array}$ & $\begin{array}{c}\text { Baja y muy } \\
\text { baja }\end{array}$ & $90.90 \%$ & $9.10 \%$ & $100 \%$ & 1 & 0 & 1 & Licenciatura (1) \\
\hline $\begin{array}{c}\text { Telese- } \\
\text { cundaria } 2\end{array}$ & $\begin{array}{l}\text { Telese- } \\
\text { cundaria }\end{array}$ & Media & $73.60 \%$ & $26.40 \%$ & $100 \%$ & 3 & 1 & 2 & Licenciatura (3) \\
\hline Total & & & & & & 19 & 15 & 4 & \\
\hline
\end{tabular}

Fuente: Elaboración propia con información de PLANEA (2017).

${ }^{a}$ El porcentaje de alumnos en el estado de Tamaulipas es de $77.7 \%$ para el nivel 1 y 2 y 22.3 para el nivel 3 y 4 .

\section{Procedimiento y análisis de datos}

Para la recolección de datos se contó con autorización de la Dirección de Secundarias de la Secretaría de Educación Pública en el estado, así como de los directores de cada escuela. El proceso se llevó a cabo durante dos meses, en los que se acudió a las diferentes instituciones en ambos turnos para realizar las entrevistas a los profesores. Una vez concluidas, se transcribieron y se determinaron las subdimensiones para cada una de las dimensiones y se realizó el análisis de casos cruzados. Éste consiste en que el investigador se centra en algunos temas clave (o 
análisis de temas), no para generalizar más allá del caso, sino para comprender su complejidad; busca identificar problemas dentro de cada caso, para luego localizar temas comunes que trasciendan los casos.

Un formato típico es, en primer lugar, proporcionar una descripción detallada de cada uno de los casos: contexto y descripción, después se destacan los temas relevantes: análisis de temas dentro del caso. Posteriormente, se elabora un análisis temático a través de los casos, llamado análisis de temas cruzados, así como afirmaciones o una interpretación (el análisis temático seguido adoptó una postura ética). En la fase interpretativa final, el investigador informa sobre el significado de la problemática planteada, ya sea que se trate de aprender sobre el tema o sobre una situación inusual (Creswell, Poth, 2018; Yin, 2009)

En la tabla 2 se presentan las dimensiones de análisis, sus definiciones y fundamentos teóricos y subdimensiones establecidas a partir del conjunto de datos.

Tabla 2. Dimensiones, fundamentos teóricos, definición y subdimensiones

\begin{tabular}{|c|c|c|c|}
\hline Dimensión & Fundamentos teóricos & Definición & Subdimensiones \\
\hline $\begin{array}{l}\text { Noción sobre } \\
\text { comprensión } \\
\text { de múltiples } \\
\text { textos }\end{array}$ & $\begin{array}{l}\text { Procesos y habilidades } \\
\text { en la comprensión de docu- } \\
\text { mentos múltiples (Rouet, } \\
\text { 2006; Britt et al., 2018) }\end{array}$ & $\begin{array}{l}\text { Se refiere a las ideas, percep- } \\
\text { ciones o creencias que tienen } \\
\text { los profesores sobre los pro- } \\
\text { cesos y habilidades de la com- } \\
\text { prensión de múltiples textos }\end{array}$ & $\begin{array}{l}\text { Idea } \\
\text { Percepciones } \\
\text { Creencias }\end{array}$ \\
\hline $\begin{array}{l}\text { Prácticas de } \\
\text { enseñanza }\end{array}$ & $\begin{array}{l}\text { Modelo sociocognitivo } \\
\text { (Ruddell, Unrau, 2013). } \\
\text { Teorías implícitas/creencias } \\
\text { (Gómez-López, 2008) } \\
\text { Enseñanza de procesos es- } \\
\text { tratégicos en lectura (Alma- } \\
\text { si, King, 2012) }\end{array}$ & $\begin{array}{l}\text { Describe las estrategias que } \\
\text { guían las actividades o tareas } \\
\text { dentro y fuera del aula que } \\
\text { impliquen la comprensión de } \\
\text { múltiples textos. Asimismo, las } \\
\text { estrategias que enseña a sus } \\
\text { alumnos, además de las fuen- } \\
\text { tes, textos y temas que utiliza } \\
\text { que favorezcan la CMF. Alude } \\
\text { también si enseña a sus estu- } \\
\text { diantes a evaluar las fuentes } \\
\text { que se utilizan. }\end{array}$ & $\begin{array}{l}\text { Actividades o tareas extraclase } \\
\text { Estrategias o actividades } \\
\text { Enseñar a los alumnos estrate- } \\
\text { gias LCMF } \\
\text { Solicitar a los alumnos tareas } \\
\text { que implican la LCMF } \\
\text { Tipos de fuentes utilizadas } \\
\text { Tipos de texto utilizados para } \\
\text { favorecer LCMF } \\
\text { Tipos de temas abordados para } \\
\text { favorecer LCMF } \\
\text { Enseñar a los alumnos a evaluar } \\
\text { las fuentes. }\end{array}$ \\
\hline Evaluación & $\begin{array}{l}\text { Procesos relevantes en la } \\
\text { comprensión de documentos } \\
\text { múltiples (Rouet, 2006) } \\
\text { La práctica educativa de } \\
\text { los docentes: pensamiento, } \\
\text { interacción y reflexión. (Gar- } \\
\text { cía-Cabrero et al., 2008) } \\
\text { Estrategias docentes (Díaz, } \\
\text { Hernández, 2010). }\end{array}$ & $\begin{array}{l}\text { Se relaciona con la evaluación } \\
\text { que realiza el profesor en las } \\
\text { actividades relacionadas con } \\
\text { la LCMF (qué y cómo evalúa). } \\
\text { Puntualiza sobre si el profesor } \\
\text { evalúa las fuentes utilizadas y } \\
\text { la integración intertextual de } \\
\text { los contenidos, que realizan } \\
\text { sus alumnos en actividades y } \\
\text { tareas. También las estrategias, } \\
\text { tipos e instrumentos que utiliza } \\
\text { para evaluar la LCMF. }\end{array}$ & $\begin{array}{l}\text { Evalúa las fuentes que se utili- } \\
\text { zan para tareas/actividades } \\
\text { Aspectos que evalúa en la LCMF } \\
\text { Estrategias o instrumentos } \\
\text { para evaluar la LCMF }\end{array}$ \\
\hline
\end{tabular}

Fuente: Elaboración propia. 


\section{Resultados}

En la tabla 3, se organizó la información por casos y dimensiones con la intención de tener una visión global de los datos y, con ello, más adelante se analizan de forma combinada para comparar e informar de manera comprensiva los resultados obtenidos. Tójar (2006) describe este tipo de tablas como metamatriz descriptiva, ya que en una misma tabla se recogen rasgos o categorías principales de varios casos para comprender globalmente las divergencias entre casos o situaciones, como se observa a continuación: 
Tabla 3. Metamatriz descriptiva

\begin{tabular}{|c|c|c|c|}
\hline Casos & $\begin{array}{l}\text { Noción de com- } \\
\text { presión intertex- } \\
\text { tual }\end{array}$ & Enseñanza de la comprensión intertextual & Evaluación \\
\hline 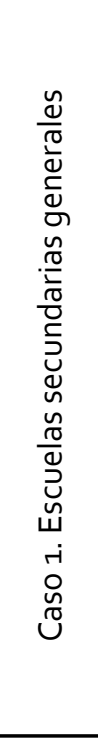 & $\begin{array}{l}\text { Los profesores } \\
\text { describen proce- } \\
\text { sos que consisten } \\
\text { en comprender } \\
\text { primeramente } \\
\text { cada uno de los } \\
\text { textos y posterior- } \\
\text { mente, comparar } \\
\text { entre textos, esta- } \\
\text { bleciendo vínculos } \\
\text { entre las propias } \\
\text { fuentes y el conte- } \\
\text { nido. }\end{array}$ & $\begin{array}{l}\text { Actividades extraclase: Refieren tareas que } \\
\text { promueven comprensión intratextual. } \\
\text { Actividades en clase: detallan actividades } \\
\text { individuales. } \\
\text { Enseña a sus alumnos estrategias de LCMF: } \\
\text { Enseña estrategias enfocadas a varios tex- } \\
\text { tos. } \\
\text { Solicita tareas que implican LCMF: Señala que } \\
\text { sí solicita tareas que implican la LCMF, pero } \\
\text { describen tareas que implican una fuente. } \\
\text { Tipos de fuentes que solicita: Señalan libros, } \\
\text { libro de texto, internet, revistas } \\
\text { Tipos de textos: Aluden a textos expositivos y } \\
\text { narrativos. } \\
\text { Tipos de temas: Utilizan temas del interés del } \\
\text { alumno. } \\
\text { Enseña a sus alumnos a evaluar fuentes: No } \\
\text { enseñan a sus alumnos a evaluar fuentes, } \\
\text { sólo hacen recomendaciones. }\end{array}$ & $\begin{array}{l}\text { Evalúa las fuentes que se utilizan en } \\
\text { tareas/actividades: Señalan que sí, } \\
\text { pero no detallan criterios. } \\
\text { Aspectos que evalúa en la LCMF: } \\
\text { Refiere que evalúa redacción, argu- } \\
\text { mento y opinión. } \\
\text { Estrategias o instrumentos para } \\
\text { evaluar la LCMF: Refieren rúbricas, } \\
\text { listas de cotejo y observación } \\
\text { Tipos de evaluación: Refiere la coe- } \\
\text { valuación, sumativa y continua, } \\
\text { autoevaluación. }\end{array}$ \\
\hline 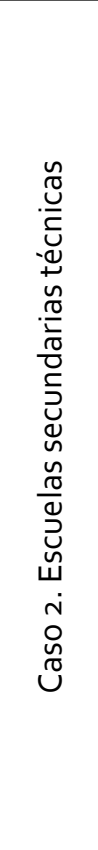 & $\begin{array}{l}\text { Los profesores } \\
\text { describen ac- } \\
\text { tividades que } \\
\text { implican la LCMF, } \\
\text { mientras que el } \\
\text { resto, se enfocan } \\
\text { en describir proce- } \\
\text { sos que se refieren } \\
\text { a la comprensión } \\
\text { intratextual, }\end{array}$ & $\begin{array}{l}\text { Actividades extraclase: Describen tareas que } \\
\text { implican la integración de fuentes de forma } \\
\text { oral y escrita que promueven la LCMF. } \\
\text { Actividades en clase: Describen actividades } \\
\text { individuales y combinan individuales y cola- } \\
\text { borativas. } \\
\text { Enseña a sus alumnos estrategias de LCMF: } \\
\text { Describen estrategias enfocadas a varios tex- } \\
\text { tos, el resto a un texto o promover hábitos. } \\
\text { Solicita tareas que implican LCMF: Comentan } \\
\text { que sí solicitan tareas que implican LCMF y } \\
\text { describen tareas relacionadas. } \\
\text { Tipos de fuentes: Señalan libros, libro de tex- } \\
\text { to, internet, revistas. } \\
\text { Tipos de textos: La mayoría utiliza narrativos. } \\
\text { Tipos de temas: Utilizan temas relacionados } \\
\text { con otras asignaturas. } \\
\text { Enseña a sus alumnos a evaluar fuentes: No } \\
\text { enseñan a sus alumnos a evaluar fuentes, } \\
\text { sólo hacen recomendaciones. (1) enseña a } \\
\text { sus alumnos a evaluar las fuentes a través del } \\
\text { sitio, autor y editorial. }\end{array}$ & $\begin{array}{l}\text { Evalúa las fuentes que se utilizan en } \\
\text { tareas/actividades: Señalan que no, } \\
\text { porque no proveen el material, no } \\
\text { les da tiempo. } \\
\text { Aspectos que evalúa en la LCMF: } \\
\text { Refieren aspectos de ortografía, } \\
\text { aspectos que implican la compara- } \\
\text { ción de fuentes, argumentación. } \\
\text { Estrategias o instrumentos para } \\
\text { evaluar la LCMF: Refieren rúbricas, } \\
\text { listas de cotejo y observación } \\
\text { Tipos de evaluación: Utilizan eva- } \\
\text { luación formativa y sumativa, } \\
\text { heteroevaluación, listas, autoeva- } \\
\text { luación y coevaluación. }\end{array}$ \\
\hline
\end{tabular}




\begin{tabular}{|c|c|c|c|}
\hline 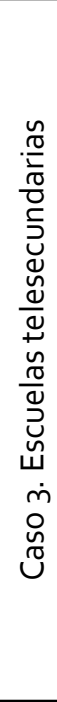 & $\begin{array}{l}\text { Los profesores } \\
\text { aluden a nociones } \\
\text { de comprensión } \\
\text { intertextual }\end{array}$ & $\begin{array}{l}\text { Actividades extraclase: Describen búsqueda } \\
\text { de información, sin precisar productos. } \\
\text { Actividades en clase: Describen actividades } \\
\text { individuales y colaborativas. } \\
\text { Enseña a sus alumnos estrategias de LCMF: } \\
\text { Describen que promueven hábitos } \\
\text { Solicita tareas que implican LCMF: Comentan } \\
\text { que solicitan tareas que implican la LCMF y } \\
\text { las tareas que describen implican la lectura } \\
\text { de un solo texto. } \\
\text { Tipos de fuentes que solicita: Señalan libros, } \\
\text { libro de texto, internet, revistas. } \\
\text { Tipos de textos: La mayoría utiliza narrativos. } \\
\text { Tipos de temas: Utilizan temas de otras asig- } \\
\text { naturas. } \\
\text { Enseña a sus alumnos a evaluar fuentes: No } \\
\text { enseñan a sus alumnos a evaluar fuentes, } \\
\text { sólo hacen recomendaciones. }\end{array}$ & $\begin{array}{l}\text { Evalúa las fuentes que se utilizan } \\
\text { en tareas/actividades: Refieren } \\
\text { que no lo hacen porque no se les } \\
\text { había ocurrido, sí evalúa autores, } \\
\text { fuentes, sitios. } \\
\text { Aspectos que evalúa en la LCMF: } \\
\text { Comentan aspectos de ortografía, } \\
\text { limpieza y redacción. } \\
\text { Estrategias o instrumentos para } \\
\text { evaluar la LCMF: Comentan crite- } \\
\text { rios de evaluación como tareas, } \\
\text { participación, preguntas orales, } \\
\text { exámenes. } \\
\text { Tipos de evaluación: No detallan } \\
\text { tipos de evaluación, mencionan } \\
\text { criterios. }\end{array}$ \\
\hline 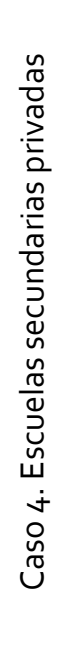 & $\begin{array}{l}\text { Los profesores } \\
\text { refieren procesos } \\
\text { que implican la } \\
\text { búsqueda y lectu- } \\
\text { ra de más de una } \\
\text { fuente. }\end{array}$ & $\begin{array}{l}\text { Actividades extraclase: Describen tareas que } \\
\text { implican la integración de fuentes de forma } \\
\text { escrita y que promueven la CMF } \\
\text { Actividades en clase: Describen actividades } \\
\text { individuales } \\
\text { Solicita tareas que implican LCMF: Comentan } \\
\text { que sí solicitan tareas que implican la LCMF y } \\
\text { describen tareas que se relacionan con ello } \\
\text { Tipos de fuentes que solicita: Señalan libros, } \\
\text { libro de texto, internet, revistas y videos. } \\
\text { Tipos de textos: La mayoría utiliza textos } \\
\text { argumentativos e informativos. } \\
\text { Tipos de temas: Mencionan que utilizan te- } \\
\text { mas del interés del alumno. } \\
\text { Enseña a sus alumnos a evaluar fuentes: No } \\
\text { enseñan a sus alumnos a evaluar fuentes, } \\
\text { sólo hacen recomendaciones. }\end{array}$ & $\begin{array}{l}\text { Evalúa las fuentes que se utilizan en } \\
\text { tareas/actividades: Comentan que } \\
\text { sí, no detallan sólo verifican infor- } \\
\text { mación de internet. } \\
\text { Aspectos que evalúa en la LCMF: Re- } \\
\text { fieren la integración o relación de } \\
\text { las fuentes, elaborar argumento, } \\
\text { Estrategias o instrumentos para } \\
\text { evaluar la LCMF: Utilizan lista de } \\
\text { cotejo, rúbrica y observación, des- } \\
\text { criben criterios como participación } \\
\text { y trabajo en equipo. } \\
\text { Tipos de evaluación: Coinciden en } \\
\text { utilizar la coevaluación. }\end{array}$ \\
\hline
\end{tabular}

Fuente: Elaboración propia.

\section{Noción de comprensión}

La comprensión de múltiples textos alude al conocimiento que posee el profesor acerca de los procesos cognitivos (evaluación de la fuente y establecimiento de vínculos intertextuales) y las habilidades que deben poner en marcha los estudiantes para construir significados de temas o problemas de mayor complejidad y que se basan en información presentada, no en un único texto sino en múltiples fuentes (Britt et al., 2018; List, Alexander, 2017).

A través del análisis, se encontró que los profesores de las secundarias privadas (3) son quienes tienen mayor claridad sobre el tema de comprensión intertextual, pues cuando describen su noción sobre la LCMF hacen referencia a procesos que implican la búsqueda y lectura de más 
de una fuente: "Es un artículo de opinión el que hacen, no necesitan nada más su opinión sino también argumentarla y para eso necesitan investigar y les pido que investiguen en internet y en libros [...] hacen un cuadro comparativo y ponen los diferentes textos que leyeron y ponen lo que entendieron de esos textos" (SECPRIVAR-ESP13).

El caso de las escuelas telesecundarias es similar, dos de los tres profesores aluden a procesos de comprensión intertextual: "pues de que es muy bueno porque así compara diferentes puntos de vista de los autores. Es lo que pienso" (TELSECPCN-ESP15).

Por su parte, en las secundarias técnicas, la mitad de los profesores (4) describen actividades que implican la LCMF: "El alumno tiene que investigar X tema, precisamente de diversas fuentes y se le da la idea de que lo puede consultar en libros, en revistas, en periódicos, en el mismo internet y que con base a lo que el indague tiene que elaborar un texto que es un ensayo en el cual el aporte sus ideas, sus argumentos" (SECTECAL-ESP8). Mientras que el resto (4) se enfocan en describir procesos que se refieren a la comprensión intratextual, es decir, hacen referencia a un solo texto: "A veces por la premura del tiempo, te digo, aquí traen periódico, pero luego ya timbran, la siguiente clase ya no lo trajeron" (SECTECAL-ESP7).

En el caso de las secundarias generales, sólo uno de los tres profesores describe procesos que consisten en comprender primeramente cada uno de los textos $y$, posteriormente, comparar entre textos estableciendo vínculos entre las propias fuentes y el contenido: "seleccionar un tema, luego buscar lo que son información que nos hablen sobre esos temas, y luego ver cómo maneja cada uno los autores, dichos temas y que el alumno ya lo compare" (SECGPRR-ESP3).

Con base en lo anterior, se puede señalar la importancia del conocimiento global de la asignatura por parte del profesor, pues éste tiene un impacto en el uso de determinados métodos de enseñanza y estrategias que promuevan la construcción de significados dependiendo de la disciplina (García-Cabrero et al., 2008; Gómez-López, 2008; Rudell, Unrau, 2013).

\section{Prácticas de enseñanza de la comprensión de múltiples textos}

La enseñanza de la comprensión de múltiples textos implica que el profesor, además de conocer en qué consiste la LCMF, conozca el cómo implementar de forma adecuada estrategias, métodos y actividades que promuevan el desarrollo de la competencia de la LCMF en los estudiantes. A continuación, se describen los temas clave que se encontraron en cada una de las secundarias, de acuerdo con las subdimensiones que conforman esta dimensión.

\section{Actividades o tareas extraclase}

Dentro de las actividades o tareas extraclase que los profesores consideran que los alumnos requieren leer más de un texto, se encuentran dos tipos de actividades o tareas: a) las que implican la integración de fuentes de forma escrita y $b$ ) las que implican la integración de fuentes de forma oral. En el primer caso se subdividen en actividades que requieren la comprensión intratextual e intertextual. 
En el caso de las secundarias generales los profesores (2), refieren tareas que implican la integración de fuentes escritas; sin embargo, describen tareas como monografías y biografías que promueven más una comprensión intratextual: "sí, este, pues hasta ahorita lo que llevamos, ya hemos visto las monografías, el tema de mitos y leyendas que también ellos navegan, verdad. Bueno son los que recuerdo ahorita" (SECGPRR-ESP2).

Caso similar es el de los profesores de telesecundarias (3), que sólo describen la búsqueda de información, sin comentar los fines o productos finales que se solicitan después de dicha búsqueda: "pues conviene que vea lo del libro que viene muy sencillo, que lo investigue en internet, y en internet pues hay muchas fuentes también ahí, ellos eligen cuál les parece mejor" (TELSECPCN-ESP15). Sin embargo, no se observan procesos relacionados con la resolución de tareas a partir de múltiples textos. De acuerdo con los planteamientos teóricos señalados, en términos cognitivos, la tarea puede inducir al establecimiento de diferentes tipos de relación intertextual, por ejemplo, tareas que demandan la formulación de una explicación implican una relación intertextual de complementariedad, mientras que tareas argumentativas como la construcción de una opinión demandan inferir una relación intertextual contradictoria (Britt et al., 2018).

Es de notar que, en las secundarias técnicas, los profesores (5) describen tareas que implican la integración de fuentes de forma oral y escrita que promueven la LCMF, puesto que hablan de ensayos, artículos, cuadros comparativos, mesa redonda y reportajes: "Pues se les encarga la actividad y ellos la traen, pero luego se hace un cuadro comparativo para ver qué es lo que dice un autor determinado y se empiezan a sacar las ideas principales sobre ese tema" (SECTECAL-ESP5). Mientras que un profesor de la secundaria privada describe tareas que implican la integración de fuentes de forma escrita, tales como ensayos, artículos de opinión y reportajes: "Cuando les encargo hacer ensayos, tienen que leer en varias fuentes de información, cuando son ensayos, [...] y ahorita estamos viendo el reportaje, ahí también ya les encargué que leyeran diferentes fuentes, porque pues lo tienen que hacer para complementar su propio punto de vista" (SECPRIVAR-ESP13).

\section{Estrategias o actividades}

En esta subdimensión, los profesores describen las estrategias o actividades que desarrollan en clase para favorecer la LCMF; se distinguen dos tipos: individuales y colaborativas. En las secundarias generales, dos de los profesores sólo detallan actividades individuales, de manera semejante a las secundarias técnicas: "si van a realizar una monografía, este pues yo por lo general los pongo en equipo, [...] una de las actividades que se realizaron dentro de mitos y leyendas hicieron cuadros comparativos, verdad" (SECGPMAC-ESP2). En las técnicas, la mayoría de los profesores (5) describen actividades individuales y del tipo ensayo, cuadros comparativos, análisis de diferentes noticias en distintos periódicos. Señalan actividades que se relacionan más con 
la LCMF "esta última que vimos de una noticia tuvimos que ver distintas noticias de distintos periódicos para que formáramos nuestro propio criterio" (SECTECAL-ESP6); y en menor medida (3 profesores) combinan actividades colaborativas e individuales; pero también en las escuelas privadas los docentes (3) mencionan sólo actividades individuales: "lo que hago es explicarles que es la lectura comparativa y que no nada más es leerlo, copiar y pegar de internet, lo que sí les pido es que parafraseen, que sepan qué están leyendo y pues lo que lean sea verídico" (SECPRIVAR-ESP13).

Caso contrario a lo anterior, los profesores de las escuelas telesecundarias (3) reportan actividades tanto individuales como colaborativas: "Hay la lectura en grupo, la lectura individual y en eso hay, en equipos, trabajos en equipo. Resúmenes, síntesis, puntos de vista, debates" (TELSECPSH-ESP16).

La importancia de las estrategias o actividades individuales radica en el entrenamiento del paso a paso que modela el profesor y que logrará que los alumnos lo dominen; sin embargo, en las respuestas de los profesores no se encontró evidencia sobre si el profesor demuestra o modela las estrategias a través de una enseñanza explícita (Almasi, King, 2012).

\section{Enseñar a los alumnos estrategias de LCMF}

Además de dar la instrucción para que el alumno realice alguna actividad, es importante que el estudiante conozca estrategias que le permitan elaborar tareas que promueven la LCMF. Por ello se les preguntó a los profesores si enseñan a sus alumnos estrategias para favorecer la LCMF. Entre las respuestas se encontraron tres tipos de estrategias que realizan: a) enfocadas a un texto; b) enfocadas a varios textos; y c) enfocadas a promover hábitos de lectura. Uno de los profesores de la secundaria técnica y uno de la escuela telesecundaria señalaron que no enseñan a sus alumnos este tipo de estrategias. En las escuelas telesecundarias se encontró que los profesores promueven estrategias orientadas a un solo texto: "Primero las ideas primarias, ideas secundarias y sobre eso, ellos elaboran un texto. Y ellos le ponen el tema que ellos quieren" (TELSECPCN-ESP17). Desafortunadamente, orientarse a analizar un solo texto va en detrimento de enseñar estrategias que contribuyan a la LCMF, pues no brinda oportunidades para que los estudiantes aprendan las condiciones en las cuales se puede usar una estrategia determinada, ni para la conciencia metacognitiva con respecto al uso de la estrategia (Almasi, King, 2012).

En las secundarias privadas, uno de los profesores describe estrategias enfocadas a varios textos (tablas comparativas) "sí, lo que les pongo comúnmente es un cuadro comparativo, para que ahí pongan el título del texto y me pongan, este, de cada uno y comparen las diferencias como sus semejanzas del aspecto que encuentre" (SECPRIVAR-ESP13), mientras que el resto (2) enfocadas a un sólo texto: "sí, precisamente ideas principales, ideas secundarias manejamos mucho, resúmenes, síntesis, te digo, son las que más manejamos" (SECPRIVAR-ESP12). En las secundarias técnicas sólo tres de los profesores describen estrategias enfocadas a varios textos: 
"Sí, por ejemplo, cuando manejamos algún tema por equipo, se tiene la previa investigación, en algunos momentos se pide diferentes fuentes, por autor, para hacer la comparación en equipos" (SECTECAL-ESP9); mientras que el resto de estrategias están enfocadas a un texto y a promover hábitos de lectura: "hacemos resúmenes, dentro de los resúmenes siempre les explicamos que cada párrafo tiene una idea principal [...] por ejemplo, en que me ubiquen todos los verbos que dijimos ya, o sea, que el verbo es la acción, me subrayan todos los verbos y hacemos una lista de verbos, de estos verbos hacemos otro cuadro y en ese cuadro los niños van a ir enlazando todas las acciones que están viendo y cuando acuerdan en el texto o en el cuadro se dan cuenta que ya hicieron un resumen" (SECTECAL-ESP6).

\section{Solicitar a los alumnos tareas que implican la LCMF}

En las secundarias generales, uno de los profesores señaló que sí solicita a sus alumnos tareas que implican la LCMF; sin embargo, no describe las tareas que realiza: "sí, como tareas tales no porque no las hacen, pero sí lo hacemos dentro de clase" (SECGPRR-ESP3). El resto de los profesores (2) también señalaron que sí solicitan este tipo de tareas y describieron tareas que implican la lectura de un texto y de varios textos: "pues son la elaboración de resúmenes, este, por ejemplo, ensayos, también como ahí en los ensayos ellos tienen que, pues según los elementos que contiene la introducción, su desarrollo, entonces tienen que ir leyendo" (SECGPMAC-ESP2). En las secundarias técnicas, dos profesores dijeron que no solicitan este tipo de tareas a sus estudiantes: "En verdad tarea no, siempre lo hacemos aquí porque no la hacen la tarea" (SECTECAL-ESP4). Otros dos señalaron que sí, pero las tareas que describen están enfocadas a la lectura de un texto: "Yo les puedo decir, desde que me hagan una línea del tiempo y contrastar la información con otros compañeros que hagan una línea del tiempo o que me hagan un mapa conceptual, un mapa mental y después decir, a ver, a ti qué información te faltó" (SECTECLA-ESP11); mientras que el resto (4) relata que sí solicitan este tipo de tareas y las que mencionan implican la lectura comparativa de varias fuentes, y además comentan que los estudiantes las desarrollan tanto individual como colaborativamente: "todas las tareas se llevan a cabo en el salón, si lo manejamos por tema pues se lleva en equipo y todos tienen la obligación de traer la investigación de diferente fuente, ahí mismo se ponen de acuerdo, los coordinamos y ellos traen la información y en el salón hacemos un análisis comparativo de cada una de las fuentes y se llega a una sola conclusión" (SECTECAL-ESP9).

En las secundarias privadas, dos de los profesores describen tareas solicitadas a sus alumnos y que implican la lectura comparativa de varias fuentes: "Sí, pues cuando investigan para hacer lo del ensayo, lo del artículo de opinión, el reportaje en este caso que lo están manejando" (SECPRIVAR-ESP13). En las escuelas telesecundarias dos de los profesores describen tareas solicitadas que implican la lectura de una fuente: "leemos, sacamos ideas principales, ideas secundarias para elaborar al último una conclusión" (TELSECPSH-ESP17); mientras que el resto (2), 
a pesar de señalar que sí solicitan a sus estudiantes tareas que implican la LCMF, sólo describen actividades poco o nada relacionadas con el tema: "sí y a veces también de lo que saben sus papás, sus abuelos" (TELSECPCN-ESP15). Esto sugiere que las tareas o actividades que se solicitan poco promueven la construcción de esquemas de conocimiento de fondo que ayudan al lector en la construcción del significado y el establecimiento de relaciones intertextuales (Britt et al., 2018; Ruddell, Unrau, 2013).

\section{Tipos de fuentes utilizadas}

En los tipos de fuentes que los profesores utilizan para favorecer la LCMF es importante destacar que en todas las variantes de secundarias los profesores aluden a libros, libro de texto e internet. Los de secundarias generales, técnicas y telesecundarias comentan que además utilizan revistas y periódicos, excepto las secundarias privadas; en este caso, uno de los profesores (SECPRIVAR-ESP12) comentó que utilizaba videos.

\section{Tipos de textos que se utilizan para favorecer la LCMF}

Durante el proceso de enseñanza de la LCMF es importante considerar los tipos de texto que se utilizan, tales como: argumentativos, narrativos, expositivos e informativos. Los profesores de las escuelas secundarias generales aluden a textos expositivos y narrativos: "Son textos expositivos e informativos, son generalmente porque, por ejemplo, si yo los hago en las obras literarias ellos tienen mucha renuencia" (SECGPMAC-ESP1), mientras que en las secundarias técnicas y telesecundarias se utilizan con mayor frecuencia los textos narrativos "Sí, pues principalmente como es español, narrativos, verdad, principalmente, básicamente, aunque también hay ocasiones en que manejamos este textos de la lírica, verdad, poesías" (SECTECAL-ESP8). Es de notar que en la secundaria privada los docentes describen textos argumentativos e informativos: "sí, pues yo creo que de todo manejamos, vemos también noticias periodísticas, los artículos, te digo, el programa viene muy rico en eso que se maneja mucho, o sea los diferentes tipos de textos y que viene mucho comparar las fuentes, se aplican también diferentes estrategias para comprensión lectora, entonces..." (SECPRIVAR-ESP12).

La importancia de los tipos de texto estriba en los patrones textuales o estructuras que guarda cada uno de ellos, así como su función comunicativa, pues permite al lector dirigir su atención para realizar inferencias y utilizar estrategias diferenciadas para comprender la información. Por ejemplo, los textos narrativos siguen un patrón de estructura única (personajes, contexto de la historia, objetivo, problema, acciones, soluciones y lección aprendida) (Williams, 2018). Mientras que los textos expositivos, a diferencia de los narrativos, pueden tener una estructura en diferentes sentidos comunicativos, tales como la descripción, secuencia, comparación, contraste, causa-efecto y problema-solución. Esta variedad de estructuras poco familiares es lo que resulta problemático para los alumnos (Roehling et al., 2017). Los profesores sólo mencionan el tipo de texto, pero no detallan el propósito de incorporar uno u otro, para el desarrollo de la LCMF. 


\section{Tipos de temas que se utilizan para favorecer la LCMF}

Los temas que los profesores de los diferentes tipos de secundaria utilizan en sus actividades o tareas para favorecer la LCMF se dividen en los que se relacionan con el interés de los alumnos y los temas que se ven en otras asignaturas. La importancia del interés del alumno en la elección del tema radica en que contribuye a la motivación y el compromiso del lector en la lectura (List, Alexander, 2017).

En las secundarias generales los profesores destacan que utilizan temas relacionados con el interés del alumno: "Nunca hago actividades que no sean de interés de los alumnos, primero pregunto sobre qué temas quieren ellos informarse, entonces, dependiendo de los temas que ellos aborden, entonces ahora sí ya de esos procedemos a adecuarlos a las actividades que vamos a hacer" (SECGPMAC-ESP1). Lo anterior difiere de los profesores de las secundarias técnicas, quienes en su mayoría (5) utilizan temas que se relacionan con otras asignaturas: "Ay, mira, el anterior que hicimos en la primera parte del proyecto que fue de resúmenes, ellos tenían que de alguna manera buscar la información de un tema que ellos elijan dentro de ciencias" (SECTECALESP6). En las escuelas telesecundarias, tres de los cuatro profesores entrevistados utilizan temas de interés de los alumnos: "Pues es que son temas que ellos elijan, yo me voy más a los temas que hay aquí en la comunidad, que son drogas, alcoholismo, embarazos a temprana edad. Ellos me elijen esos tipos de temas, a lo que ellos están más de cerca" (TELSECPSH-ESP17).

Igualmente, en las secundarias privadas, todos los profesores (3) mencionan que utilizan temas relacionados con el interés del alumno: "¿Qué tipos de temas? temas de interés de ellos y sobre todo, temas actuales y que nos afectan a todos, como, yo utilizo mucho los temas de contaminación, corrupción, temas actuales y que nos aquejan a todos" (SECPRIVAR-ESP14), y cuando se hace referencia a otras asignaturas, destaca que la mayoría menciona la asignatura de Ciencias.

\section{Enseñar a los alumnos a evaluar las fuentes}

La LCMF implica que el alumno sea capaz de evaluar (criterios como: fiabilidad del sitio de publicación, credibilidad del autor, etc.) diferentes fuentes sobre un tema que le permitan entender y emitir una opinión o juicio sobre el mismo. Dentro del perfil de egreso de educación básica, se menciona que el egresado será capaz de evaluar las diferentes fuentes de información a las que tiene acceso (SEP, 2017). En este sentido, ahí radica la importancia de que los estudiantes aprendan a evaluar de forma crítica la información que encuentran.

Cuando se les preguntó a los profesores de los diferentes tipos de secundarias, las respuestas en su mayoría estuvieron orientadas más hacia recomendaciones de búsqueda o proveer la información ellos mismos a los estudiantes. Las secundarias generales, técnicas, telesecundarias y privadas coinciden en que no enseñan a sus alumnos a evaluar las fuentes que solicitan, sólo hacen recomendaciones de sitios o de deducción de la veracidad de la información. 
En el caso de las secundarias técnicas, la mayoría de los profesores (7) mencionan que hacen recomendaciones a los alumnos sobre los sitios que pueden visitar, o bien, que deduzcan la veracidad con el contenido de la fuente: "Es que desde antes, yo les pongo ejemplos y les digo, a ver, ustedes que andan en Face, que entran mucho a Face, díganme si lo que dice el debate es cierto o no y ya ellos hasta eso han ido creando su, ya saben más o menos que fuentes no son confiables, de ahí no quiero nada, les digo, busquen, uno les dice más o menos de qué fuentes pueden obtener información" (SECTECLA-ESP11). Sólo uno de los profesores describió que enseña a sus alumnos a evaluar las fuentes a través del sitio, autor y editorial: "Entonces sería la comparación y cómo se dice, bueno, lógico el análisis crítico, verdad, los elementos que debe llevar una fuente confiable, verdad, y que sea una fuente reconocida, sobretodo reconocido en internet, porque en los libros de texto comoquiera, verdad, enciclopedia, si son revistas pues lógicamente te vas a guiar por National Geografic y ese tipo de cosas, pero cuando es de internet, tenemos un poquito más de problema" (SECTECLA-ESP11).

Se obtuvieron resultados similares con la secundaria privada, puesto que los tres profesores sólo mencionan las recomendaciones que hacen a los alumnos de sitios confiables: "para que ellos evalúen las fuentes, bueno, les sugiero qué fuentes no consultar, las que ya sabemos que son fuentes no tan fidedignas que las personas suben ahí su información, entonces esa estrategia sí les doy, que hay que consultar fuentes oficiales, verdad, que no sean tan informales, por decirlo asi" (SECPRIVAR-ESP14). También, en coincidencia con las secundarias generales, donde los profesores mencionaron que sólo recomiendan sitios, autores o deducir si es verdad preguntándose a sí mismos si es verídico lo que leen: "pero pues de preferencia nosotros les recomendamos ciertas páginas electrónicas que puedan consultar, verdad. Cuando pues es por internet y aparte la ventaja que como quiera en los libros de texto tienen algunas recomendaciones" (SECGPMAC-ESP2).

En el caso de las telesecundarias, tres de los cuatro profesores señalan que no se enseña a los alumnos a evaluar las fuentes de información: "No. [...] pues no sé, no se me ha ocurrido, pero ya ahorita que me está diciendo, pues ya como quiera lo va a tomar uno en cuenta" (TELSECPCN-ESP15); y un profesor comentó que sólo recomienda sitios confiables: "pues de hecho yo les doy el tema que vamos a investigar y más o menos les doy la página, yo les doy la página de, de donde lo van a sacar, a redactar el texto o la información. Yo les traigo ya la página, no les dejo solos" (TELSECPSH-ESP18).

Hay una brecha entre lo que debe conocer el alumno al egresar de la educación básica respecto a la evaluación de fuentes (SEP, 2017); desafortunadamente, lo que describen los docentes es que no se les ha enseñado o desconocen sobre el tema; ello sugiere que en la formación inicial, la continua y la actualización del magisterio no se ha puesto énfasis en reducir este hueco. Son pocos los profesores que comentan algunos criterios que enseñan o recomiendan a sus alumnos, sin embargo, son inconsistentes con los principios teóricos (Britt et al., 2018). 


\section{Evaluación}

\section{Evalúa las fuentes que se utilizan para tareas/actividades}

Es preciso que dentro de la evaluación que se haga sobre los productos o tareas solicitados que implican la LCMF, el docente valore las fuentes que utilizan los alumnos. En este sentido, se les preguntó a los profesores si realizan este tipo de actividades como parte de la evaluación del alumno. La mayoría de los profesores de las telesecundarias (3) afirmó que no lo hacen: "No, no las evalúo. Como quiera les dice uno que internet trae mucha información y no toda es válida y también tiene uno que saber de quién viene la información para saber, para creerle o no creerle" (TELSECPCN-ESP15); sólo uno mencionó que sí y que los aspectos que evalúa son autores, fuentes y sitios:"Pues que se apegue al tema, que se apegue lo más que se pueda al tema, revisando autores que investigó, las consultas en qué libros, en diferentes autores" (TELSECPSH-ESP16). Los profesores de las secundarias generales (3) mencionaron que sí evalúan las fuentes que utiliza el alumno; sin embargo, cuando se pregunta qué aspectos valora, sólo mencionan los sitios de donde se obtiene la información, pero no detallan algún tipo de criterio: "bueno, tienen que ser de instituciones reconocidas, sitios que ya tienen cierto prestigio. No tomo mucho así las fuentes de información como tipo blogs personales, de preferencia que sean instituciones, universidades, etc. Ese tipo" (SECGPRR-ESP3).

En el caso de las secundarias técnicas, tres de los docentes señalaron que no realizan esta evaluación; una de ellos comentó que es ella quien les provee el material: "Sí, sí se evalúan, incluso en las presentaciones que yo les traigo de PowerPoint, ahí mismo yo les traigo la página para que ellos especialmente se metan a esa página a investigar el tema" (SECTECAL-ESP5). Otro docente señala que principalmente no lo hace porque las condiciones no se lo permiten, ya que el número de alumnos que atiende es elevado y no le da tiempo: "De manera limitada, o sea, me refiero a que no puedes profundizar en esa evaluación, en ese análisis de manera muy detallada. Tienes 35 alumnos, al menos, en el turno vespertino, en la mañana son más de 40 y a veces es bien difícil evaluar como quisieras a uno por uno" (SECTECAL-ESP8).

Por su parte, en la secundaria privada los profesores (3) mencionaron que sí evalúan las fuentes, comentan que valoran aspectos como la coherencia, la confiabilidad -aunque no detallan cómo- y que se verifica la información en internet: "les pido bibliografía y les checo si realmente lo sacaron de ahí y cuando me doy cuenta que la fuente de información no es muy confiable sí se los comento" (SECPRIVAR-ESP13).

Aunado a la subdimensión anterior, si el profesor desconoce sobre la evaluación de las fuentes o no ha enseñado a sus alumnos a hacerlo, por consiguiente, al revisar un documento elaborado por el alumno, el profesor en la mayoría de los casos no lo hace. Se destaca la respuesta del profesor SECTECAL-ESP8, que señala que no tienen tiempo por las condiciones en que se encuentran. Es importante destacar las determinaciones contextuales que inciden en las decisiones que toman los profesores como agentes, pues además de la formación con la que 
cuentan, las condiciones en las que se encuentran moldean sus creencias y expectativas para la implementación en el aula de la política educativa de la enseñanza de la LCMF (Acosta-Silva, 2013; Sykes, Wilson, 2016).

\section{Aspectos que evalúa en la LCMF}

Los profesores reciben productos y tareas que implican que el alumno ha llevado a cabo la LCMF, como ensayos o artículos de opinión. Los profesores destacan dos temas clave a la hora de evaluar: la producción escrita en aspectos gramaticales y de sintaxis, y la integración de las fuentes que permitan emitir una opinión o elaborar un argumento.

En las secundarias generales, sólo un profesor señaló que, además de la redacción, evalúa el argumento y la opinión: “Esa es la ponderación que uno se le da en la cuestión de producción de textos. O sea, y allí mismo ellos por colores también me tienen que ubicar cuál es opinión, cuál es cita textual, cuál es argumento y sobre lo que están haciendo, verdad, y uno lo checa de acuerdo a las fichas de trabajo que ellos hacen" (SECGPMAC-ESP1); mientras que el resto de los docentes no detalla aspectos ni evalúa aspectos en los productos referido a la LCMF. Caso similar a los profesores de la escuela telesecundaria (4), que describen aspectos que se refieren a la ortografía, limpieza y redacción:"Bueno, lo principal, checas el trabajo, la limpieza, contenido, el juicio que emite, las conclusiones" (TELSECPSH-ESP16). Por su parte, en las secundarias técnicas, dos docentes hacen referencia a aspectos ortográficos: "primero que nada, los elementos. Que contenga los elementos que se les está pidiendo, después la letra y la ortografía ¿sí?, primer elemento la letra y la ortografía" (SECTECAL-ESP4), mientras que el resto describen aspectos generales que implican la comparación de las fuentes de información, como argumentación, análisis comparativo y comprensión del texto: "pues que me traigan la información que les pedí, eso sería lógico que vean de una fuente confiable, esos serían indicadores que se toman en cuenta para [...] para hacer un análisis comparativo y luego que la información sea relevante también" (SECTECLA-ESP11).

Es de notar que, a diferencia de los tres tipos de secundarias anteriores, los tres docentes de la secundaria privada describen aspectos que indican la integración o relación de las fuentes que le permitan emitir una opinión o elaborar un argumento, como opiniones, comparación o contraste de ideas, puntos de vista del autor y opiniones: "Del cuadro comparativo les pido que sean diferencias y semejanzas, el tipo de texto porque, a pesar de que sea el mismo texto, puede ser narrativo o argumentativo, ¿qué más?, los diferentes puntos de vista del autor y si se comparan con los que ellos pensaban" (SECPRIVAR-ESP13).

En los aspectos de la LCMF que evalúan, una buena parte de los profesores destaca la importancia o relevancia de evaluar la gramática, ortografía y limpieza, y pocos evalúan la opinión o argumento que elabora el alumno a partir de la lectura y análisis de varias fuentes. Se destaca la presencia del enfoque o postura teórica de los años sesenta, referida a la enseñanza del es- 
pañol, regida por la gramática tradicional y, en menor medida, por las prácticas sociales de la lengua, de la que parte el enfoque comunicativo actual (Barriga-Villanueva, 2011).

\section{Estrategias o instrumentos para evaluar la LCMF}

Sobre los instrumentos o estrategias que los profesores diseñan o utilizan para evaluar la LCMF, las respuestas fueron similares en las secundarias generales, técnicas y privadas, ya que la mayoría de los docentes señalan que utilizan rúbricas, listas de cotejo y observación. Por otra parte, las escuelas telesecundarias describen criterios (participaciones, tareas, entre otros) que utilizan para la evaluación: "Bueno, mira, yo utilizo rúbricas, yo utilizo a veces listas de cotejo, verdad, pero generalmente al final de cada proyecto empezamos a hacer las rúbricas, porque al momento de realizar el producto final es donde plasmas todos los aprendizajes que realizaste, entonces vamos leyendo de uno por uno y ellos hacen una coevaluación: a ver tu trabajo" (SECGPMAC-ESP1).

En la secundaria privada, dos de los profesores comentaron que utilizan lista de cotejo, rúbrica y observación: "Utilizo para las actividades, utilizo lista de cotejo para las actividades que están fácil de sí o no lo hizo. También utilizo rúbricas, eso ya para cuando quiero evaluar algo ya muy, muy preciso" (SECPRIVAR-ESP13). Otro más (SECPRIVAR-ESP14) describe criterios como participación y trabajo en equipo. Del mismo modo, se encontró que las secundarias generales y técnicas en su mayoría utilizan la lista de cotejo y rúbrica, salvo dos profesores que detallaron criterios de evaluación: "se les da puntos por cada actividad, bueno yo, en mi caso lo que es participación, bueno, por ejemplo, doy diez puntos de participación, [...] la exposición se les da también un porcentaje de 20 puntos" (SECTECLA-ESP10). Al igual que los profesores de telesecundaria. Pareciera que existe una confusión entre criterios de evaluación y estrategias e instrumentos que se utilizan para realizar la evaluación.

\section{Tipos de evaluación}

Los profesores de las secundarias generales no coincidieron en los tipos de evaluación que utilizan; mientras que uno utiliza la autoevaluación, otro la coevaluación: "La coevaluación, y yo hago la evaluación de ellos de cada proyecto, verdad. Muy poco, muy poco hago que ellos se evalúen sus propios textos porque todavía no tienen criterios como para evaluarse ellos mismos, verdad" (SECGPMAC-ESP1); y el último señaló utilizar la sumativa y continúa: "¿Cómo? ¿O sea, sumativa? o ¿a qué se refiere? [...] pues llevo una evaluación continua con los muchachos, o sea, si aplico una actividad un día"(SECGPRR-ESP3). Tres de los profesores de las escuelas telesecundarias mencionan tipos de evaluación como autoevaluación, heteroevaluación y evaluación continua: "Es evaluación continua, desde que inicia llevamos revisando sus materiales, que participen, que tengan todos sus trabajos" (TELSECPSH-ESP18). Cabe señalar que un profesor sólo comenta criterios de evaluación, pero no menciona de qué tipo: "Pues son cincuenta-cincuenta. 
La evaluación es en participación, tareas, el libro, análisis, resúmenes, lectura, todo eso vale diez y diez. Son cincuenta por ciento, diez de cada uno y cincuenta por ciento el examen, son el cien por ciento" (TELSECPSH-ESP16).

Caso contrario es el de la secundaria privada, donde los tres profesores coinciden en que utilizan la coevaluación y dos de ellos, además la autoevaluación: "autoevaluación lo utilizo ya hasta el final del proyecto, cuando ellos ya se autoevalúan de si aprendieron o no, pero normalmente es coevaluación" (SECPRIVAR-ESP13).

Respecto a los profesores de las secundarias técnicas, cinco coinciden en la evaluación formativa y sumativa: "es la formativa y la sumativa" (SECTECAL-ESP4); mientras que el resto (3) destacan la heteroevaluación, listas, autoevaluación y coevaluación: "Mira, a veces es, este, por medio de las listas, eh, por medio del cuaderno o entre ellos, heteroevaluación, sí entre ellos mismos también se evalúan" (SECTECAL-ESP5).

En la tabla 5 podemos observar la frecuencia o recurrencia de las actividades que los profesores manifiestan realizar en clase. 
Tabla 5. Distribución de frecuencias por categoría y tipo de secundaria

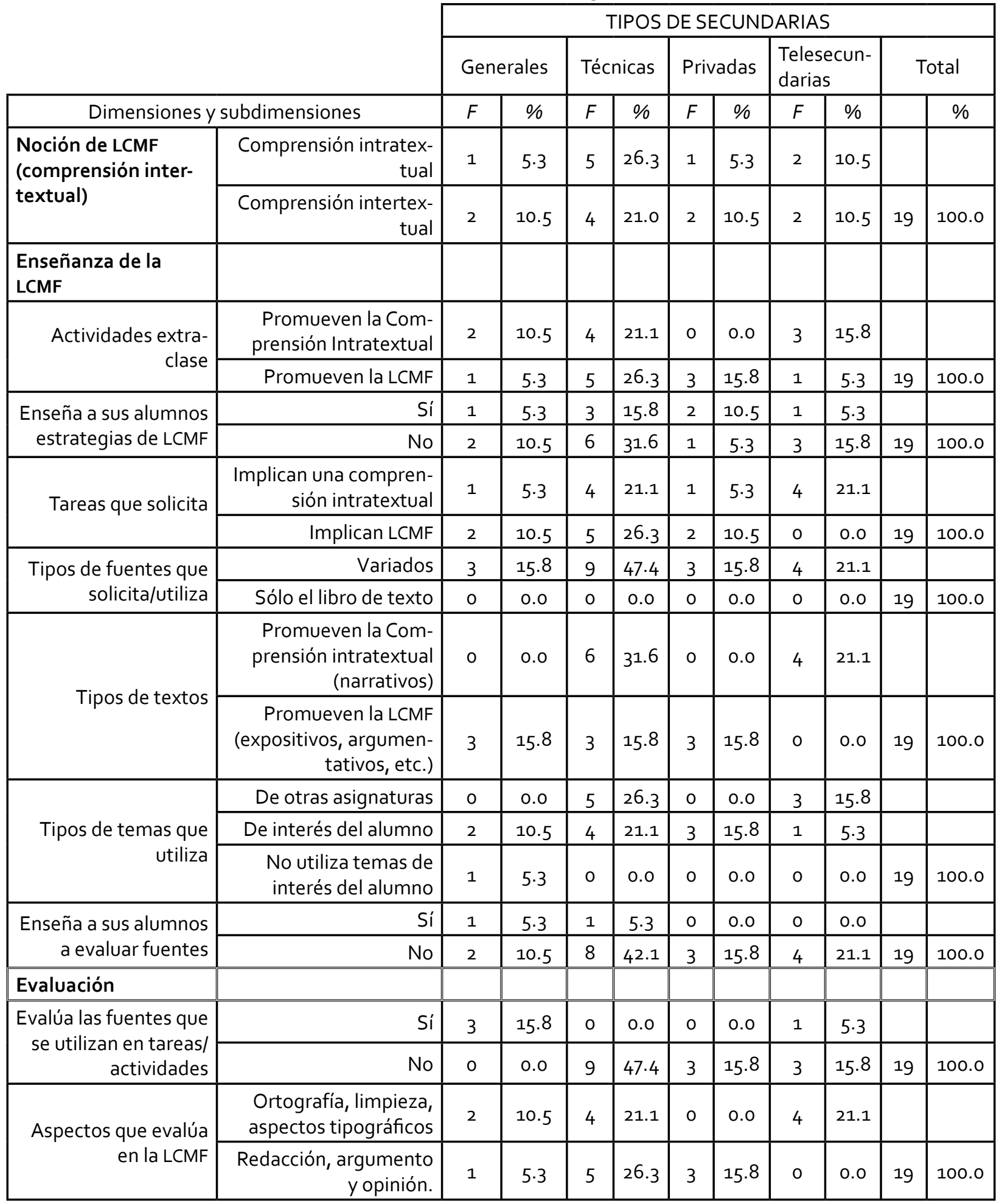




\begin{tabular}{|c|c|c|c|c|c|c|c|c|c|c|c|}
\hline \multirow{2}{*}{$\begin{array}{c}\text { Estrategias o instru- } \\
\text { mentos para evaluar } \\
\text { la LCMF }\end{array}$} & $\begin{array}{r}\text { Listas de cotejo, rúbri- } \\
\text { cas y observación }\end{array}$ & 3 & 15.8 & 9 & $47 \cdot 4$ & 2 & 10.5 & 1 & $5 \cdot 3$ & & \\
\hline & $\begin{array}{r}\text { Trabajo en equipo y } \\
\text { participación }\end{array}$ & 0 & 0.0 & 0 & 0.0 & 1 & $5 \cdot 3$ & 3 & 15.8 & 19 & 100.0 \\
\hline \multirow{5}{*}{ Tipos de evaluación } & Coevaluación & 1 & $5 \cdot 3$ & 0 & 0.0 & 3 & 15.8 & 0 & 0.0 & & \\
\hline & Sumativa y continua & 1 & $5 \cdot 3$ & 4 & 21.1 & 0 & 0.0 & 0 & 0.0 & & \\
\hline & Autoevaluación. & 1 & 5.3 & 5 & 26.3 & 0 & 0.0 & 0 & 0.0 & & \\
\hline & Formativa & 0 & 0.0 & 0 & 0.0 & 0 & 0.0 & 0 & 0.0 & & \\
\hline & No detallan & 0 & 0.0 & 0 & 0.0 & 0 & 0.0 & 4 & 21.1 & 19 & 100.0 \\
\hline
\end{tabular}

Fuente: Elaboración propia.

\section{Reflexiones finales}

El objetivo del estudio fue describir las prácticas docentes de la comprensión de múltiples textos a partir de tres dimensiones de análisis: noción, enseñanza y evaluación por modalidad educativa. De manera general, respecto a la noción de la CMT, 9 de los 19 (47.3\%) profesores entrevistados (véanse tablas 4 y 5) manifestaron tener conocimientos de los procesos y habilidades que requieren ser enseñados. Esto hace patente la necesidad de la formación del profesorado, tanto en su fase inicial como en la de actualización o continua. Por su parte, las prácticas de enseñanza que manifestaron llevar a cabo los docentes se caracterizan por la realización de tareas y actividades enfocadas principalmente en la lectura de un solo texto (52.6\%).

Entre los procesos que se requiere enseñar en este ámbito está la evaluación de la fiabilidad de las fuentes, aspecto que en menor medida es considerado por los docentes (68.4\%), aduciendo a la falta de tiempo o conocimiento sobre las mismas. En el caso de la evaluación de las actividades o tareas, se observa mayor énfasis en cuestiones gramaticales (52.6\%), en comparación con la propia integración de información (inferir relaciones intertextuales complementarias o contradictorias) y la construcción de opiniones o argumentos propios de la intertextualidad. Los hallazgos de este estudio coinciden con algunas de las prácticas identificadas en otros contextos, por ejemplo, las descritas por Broncano et al. (2011), al señalar que los profesores generan en menor medida espacios para la comprensión significativa. Así como lo referido por Litman et al. (2017), cuyas prácticas orientadas a favorecer actividades y habilidades para la argumentación propias de la CMT son escasas.

En este contexto, los resultados pueden orientar los procesos de formación y actualización del profesorado. En otras palabras, es menester orientar la enseñanza de la comprensión de múltiples textos con fundamento en la enseñanza explícita y/o modelamiento de las estrategias y habilidades que permitan a los alumnos un proceso reflexivo acerca de qué, cómo, cuándo, por qué y para qué evaluar, utilizar e integrar información proveniente de múltiples textos. Si bien las estrategias pueden enseñarse de forma general a través de la enseñanza de la lengua, estas 
también deben enseñarse de manera situada, acordes a las formas en que se generan y comunican los discursos en las disciplinas.

Por último, el estudio presenta algunas limitaciones que futuras investigaciones en esta línea pueden atender. En primer lugar, puesto que los resultados expuestos se basan únicamente en las prácticas declaradas por los profesores (lo que dicen realizar en el aula), futuros trabajos deben incorporar diferentes instrumentos que permitan la triangulación de los datos, por ejemplo, el análisis de las planeaciones didácticas que permitan observar cómo los aprendizajes esperados, planteados en el programa de estudios, se ven traducidos en el diseño de actividades, estrategias y evaluación de la LCMF, y la observación en el aula. Asimismo, sería importante evaluar el impacto de las prácticas docentes en la comprensión de múltiples textos por parte de los alumnos.

\section{Referencias}

Acosta-Silva, A. (2013). Políticas, actores y decisiones en las universidades públicas en México: un enfoque institucional. Revista de la Educación Superior, 42(165), 83-100.

Almasi, J.; S. King (2012). Teaching Strategic Processes in Reading (Second Edition). Nueva York: The Guilford Press.

Barriga-Villanueva, R. (2011). Mitos y realidades del desarrollo lingüístico en la escuela. México: El Colegio de México.

Britt, M.; J. Rouet; A. Durik (2018). Literacy beyond Text Comprehension: A Theory of Purposeful Reading. Nueva York: Routledge.

Britt, M.; J. Rouet; J. Braasch (2013). Documents as Entities. En Britt, M.; S. Goldman; J. Rouet (eds.). Reading: From Words to Multiple Texts. Nueva York: Routledge, 160-179.

Broncano, A.; E. Ciga; E. Sánchez (2011). ¿Qué papel tiene la lectura de los textos en el seno de las unidades didácticas? Cultura y Educación, 23(1), 57-74. http://dx.doi. org/10.1174/113564011794728605

Bustos, A.; C. Montenegro; A. Tapia; K. Calfual (2017). Leer para aprender: Cómo interactúan los profesores con sus alumnos en la Educación Primaria. Ocnos, 16(1), 89-106. http://dx.doi. org/10.18239/ocnos 2017.16.1.1208

Cossío, E.; G. Hernández (2016). Las teorías implícitas de enseñanza y aprendizaje de profesores de primaria y sus prácticas docentes. Revista Mexicana de Investigación Educativa, 21(71), 1135-1164. https://www.redalyc.org/articulo.oa?id=14047430007

Creswell, W.; Ch. Poth (2018). Qualitative Inquiry \& Research Design. Choosing Among Five Approaches (Fourth Edition.) EE.UU: Sage Publications. 
García-Cabrero, B.; J. Loredo; G. Carranza (2008). Análisis de la práctica educativa de los docentes: pensamiento, interacción y reflexión. Revista Electrónica de Investigación Educativa, (número especial). http://redie.uabc.mx/NumEsp1/contenido-garcialoredocarranza.html

Goldman, S.; C. Snow (2015). Adolescent Literacy: Development and Instruction. En Pollatsek, A.; R. Treimar (eds.). The Oxford Handbook of Reading. Oxford: Oxford University Press, 463-478. Gómez-López, L. (2008). Las teorías implícitas de los profesores y sus acciones en el aula. Sinéctica, 30, 1-14. https://sinectica.iteso.mx/index.php/SINECTICA/article/view/193/186

Iturra, C. (2015). La organización de la enseñanza de la lectura en las aulas chilenas. Diferencias entre profesores calificados como básicos o como competentes. Universitas Psychologica, 14(2), 535-548. https://doi.org/10.11144/Javeriana.upsy14-2.oela

List, A.; P. Alexander (2017). Analyzing and Integrating Models of Multiple Text Comprehension. Educational Psychologist, 52(3), 43-147. https://doi.org/10.1080/00461520.2017.1328309

Litman, C.; S. Marple; C. Greenleaf; I. Charney-Sirottet; M. Bolz; A. Richardson; A. Hall; M. George; S. Goldman (2017). Text-Based Argumentation with Multiple Sources: A Descriptive Study of Opportunity to Learn in Secondary English Language Arts, History, and Science. Journal of the Learning Sciences, 26(1), 79-130. https://doi.org/10.1080/10508406.2016.1256809

McMillan, J.; S. Schumacher (2005). Investigación educativa. Madrid: Pearson Educación.

Ness, M. (2011). Explicit Reading Comprehension Instruction in Elementary Classrooms: Teacher Use of Reading Comprehension Strategies. Journal of Research in Childhood Education, 25(1), 98-117. https://doi.org/10.1080/02568543.2010.531076

Roehling, J.; M. Hebert; J. Nelson; J. Bohaty (2017) Text Structure Strategies for Improving Expository Reading Comprehension. The Reading Teacher, 71(1), 71-82. https://doi.org/10.1002/ trtr.1590

Ruddell, R.; N. Unrau (2013). Reading as a Motivated Meaning-Construction Process: The Reader, the Text, and the Teacher. En Alvermann, D.; N. Unrau; R. Ruddell (eds.). Theoretical Models and Processes of Reading. Newark: International Reading Association IRA, 1015-1071.

Sánchez, E.; J. García; N. Castellano; R. de Sixte; A. Bustos; H. García-Rodicio (2008). Qué, cómo y quién: tres dimensiones para analizar la práctica educativa. Cultura y Educación 20(1), 95118. http://dx.doi.org/10.1174/113564008783781431

Secretaría de Educación Básica y Normal (2002). Reforma Integral de la Educación Secundaria. Documento base. https://coleccion.siaeducacion.org/sites/default/files/files/documentobase ries.pdf

Secretaría de la Educación Pública (2017). Modelo educativo 2016. México: SEP.

Sykes, G.; S. Wilson (2016). Can Policy (Re)form Instruction? En Gitomer, D.; C. Bell (eds.). Handbook of Research on Teaching. Washington: AERA, 851-916.

Tójar, J. (2006). Investigación cualitativa, comprender y actuar. Madrid: La Muralla. 
Treviño, E.; H. Pedroza; G. Pérez; P. Ramírez; G. Ramos; G. Treviño (2007). Prácticas docentes para el desarrollo de la comprensión lectora en primaria. México: INEE.

Williams, J. (2018) Text Structure Instruction: The Research is Moving Forward. Reading and Writing, 31(9), 1923-1935. https://link.springer.com/article/10.1007/s11145-018-9909-7

Yin, R. (2009). Case Study Research. Londres: Sage. 